\title{
Determinants of risk tolerance
}

\author{
Christoph S. Weber \\ Institute of Economics, University of Erlangen-Nuremberg, Germany
}

Email address:

christoph.weber@fau.de

\section{To cite this article:}

Christoph S. Weber. Determinants of Risk Tolerance. International Journal of Economics, Finance and Management Sciences. Vol. 2, No. 2, 2014, pp. 143-152. doi: 10.11648/j.ijefm.20140202.15

\begin{abstract}
Risk aversion is an important factor in explaining many everyday decisions. Thus, one asks which determinants can explain different attitudes towards risk. Several studies show different risk attitudes with respect to gender, age, income, and wealth (e.g. [19]). While these findings are hardly controversial, there is still some uncertainty about the effect of culture on risk tolerance. Thus, the main issue of this survey is to elaborate possible differences in risk preferences that are caused by cultural background. The main question in this context is whether religion or nationality are of importance for explaining risk attitudes. For this purpose, this study employs the German Socio-Economic Panel (GSOEP) to figure out differences in risk attitudes. Another contribution of this article is that is uses a generalized ordered logit model while others use simple linear regression models or simple logit or probit models which are not efficient. The estimations show that the cultural background does indeed have some impact on risk taking behaviour.
\end{abstract}

Keywords: Risk Tolerance, Cultural Background, Generalized Ordered Logit Model, Nationality, Religion

\section{Introduction}

Risk aversion is of great importance on a microeconomic and a macroeconomic level. First of all, risk aversion is an important factor in explaining many everyday decisions. Among these are decisions to invest money in different types of assets, the decision to enter the labour market and others like the decision to move [23]. As risk tolerance is so important in life, one asks which determinants can explain different attitudes towards risk. The question is then how risk averse people or special groups are. Several studies show different risk attitudes with respect to gender, age, income, and wealth (see, e.g., [19]). Thus, women are more risk averse than men. Risk aversion also increases also with age. Income and wealth mainly have the same effect meaning that risk tolerance increases when income and wealth increase. While these findings are hardly controversial, there is still some doubt about the effect of culture on risk tolerance. Salacuse [35] and Cummings et al. [17] compared people with different nationalities and showed that their risk preferences are in fact different. Jaeger et al. [28] found migrants to be more risk tolerant. Furthermore, Benjamin, Choi, and Fisher [7] showed that attitudes towards risk differ with respect to religion and denomination. Thus, atheists seem to be less risk averse than religious people. Although there are some studies covering the effect of nationality, race, or religion on risk tolerance, there is still a gap of studies in this area. Thus, the main issue of this survey is to elaborate possible differences in risk preferences that are caused by cultural background. The main question in this context is whether religion or nationality are of importance for explaining the risk attitudes. Furthermore, there are only few studies covering different risk attitudes with data from European countries. For this purpose, this study employs the German Socio-Economic Panel (GSOEP), which is a panel study about German households, to figure out differences in risk attitudes with respect to certain characteristics. The advantage of this survey is that it has a large number of observations which makes it easier to find specific effects. Another contribution of this article is that is employs a generalized ordered logit model which leads to more efficient results than simple OLS models.

This paper is structured as follows. Section 2 gives an overview of existing studies about attitudes towards risk. Then the data and the estimation procedure are briefly explained. In Section 4, estimation results are presented and discussed. Section 5 concludes. 


\section{Literature Review}

Some aspects of risk preferences have already been covered. The role of gender, in particular, has been analysed several times. Many studies have shown that women are generally more risk averse than men (e.g. [4, 12]) or, indeed, have different risk preferences (e.g. [16]). Other studies expand the gender issue with studies about the role of marital status. In general, married people are risk averters [38]. In married couples, wives are more risk averse than husbands [2]. Besides, risk preferences also differ among individuals who do not have children and those with children. Thus, married individuals with children are more risk averse than individuals without children. Furthermore, single mothers are less risk-seeking than single people without children [22].

Another approach to explain the amount of risk aversion is by considering the factor of age. Risk aversion is usually considered to increase with respect to age. There is indeed some evidence for this hypothesis (e.g. [32, 33]). According to Halek and Eisenhauer [25] elderly individuals are more likely to be risk averse than younger ones. Thus, risk aversion decreases with respect to age up to a certain point and then increases again [12].

Another factor which may influence risk attitudes is education. Several studies have shown the effect of education on risk aversion. According to them, people with higher education are usually less risk averse (e.g. [8]). Thus, more educated people tend be more risk prone than less educated people [36]. The question is where this effect may come from. A common assumption is that this effect is moderated by cognitive ability. In fact, people with lower cognitive ability are greater risk averters [18]. Surprisingly, financial literacy does not affect decisions [14]. Along with gender, age, and education wealth also plays a major role in explaining risk taking behaviour. The way wealth affects risk preferences has, for instance, already been discussed by Arrow [3] who proposed that absolute risk aversion decreases with respect to wealth and relative risk aversion increases with respect to wealth. While decreasing absolute risk aversion is usually supported [29], the hypothesis of increasing relative risk aversion is very controversial. There are several studies showing that relative risk aversion decreases with respect to wealth [13, 34]. However, there are also studies which find constant risk aversion [21]. This is in line with the work of Siegel and Hoban [37] who found evidence for increasing relative risk aversion. On the other hand Brunnermeier and Nagel [11] came up with the conclusion that wealth changes do not influence risk propensity. Nonetheless, the usual assumption nowadays is still that risk tolerance increases as wealth increases. Apart from wealth, income plays a role in risk preferences. People with higher income tend to be less risk averse [40]. Not only does the salary matter, however, but also tenure increases risk tolerance [1]. This may be due to higher job safety.
Previous studies have already partly revealed the role of nationality, ethnicity, and religion on risk preferences. Sung and Hanna [39] showed, for instance, that Blacks and Hispanics in the U.S. are less risk tolerant than whites. In addition, Benjamin, Choi, and Strickland [6] showed that non-immigrant Blacks are more risk averse than immigrant Blacks. Similar to this conclusion, a study by Brown [10] said that Blacks and Hispanics tend to have less stocks, whereas even low-income Whites are more risk tolerant than Blacks and Hispanics at any income level. A study with newer data supports the greater risk aversion among Hispanics, but does not find a significant effect in Blacks [15]. However, Weber and Hsee [43] concluded that culture is not the reason for different risk attitudes with respect to ethnic origin. According to them, the effect only comes from the fact that people from different cultures perceive risk differently. The reason why differences between racial groups are often found could be that ethnicity is confused with other variables such as household size and the number of children [24]. Thus, blacks and Hispanics are only more risk averse because they have larger families.

In addition, nationality matters in the decision-making processes. The behaviour in situations under risks and attitudes towards risk differ among countries. Reasons for that are education, tradition, and negative experiences in the past. For instance, the shareholder ratio in Germany is relatively low while people prefer to save money at savings banks. This might be explained by education and tradition. Salacuse [35] found that, according to their self-assessment, the French, Indians, British, Chinese and US-Americans consider themselves to be highly risk tolerant. Germans take an average position, whilst Brazilians, Mexicans and the Spanish consider themselves to be risk averters. Only the Japanese assess themselves as highly risk averse. A study by Cummings, Harnett, and Stevens [17] indicated that US-Americans are the most risk prone. In this work individuals from Central Europe (in this instance: France, Belgium, Germany, and Great Britain) are more risk averse than Scandinavians, the Spanish, and the Greeks.

Furthermore, recent cross-country comparisons revealed the surprising fact that the Chinese are more risk tolerant than US-Americans [20, 43]. However, the risk aversion of the Chinese is lower in the investment domain only. An explanation for the higher risk tolerance is the "cushion hypothesis", which says that people in a collectivist society expect to get financial help if they need it. Therefore, the Chinese are more risk prone [27]. This finding is supported by an experimental analysis by Wang and Fischbeck [42]. In contrast, a survey based on an earlier wave of the GSOEP [5] concludes that someone's nationality cannot explain his or her risk tolerance. This partly contradicts the effect that migrants are more risk tolerant [25, 28]. The different risk preferences between people with different citizenships can be explained by some other factors. Among these factors are religiousness and religion which have a significant effect on risk aversion. In addition to 
previous studies, the findings are not only that religious people are more risk averse than non-religious people, but also that among religious people Christians are less risk averse than Muslims [7]. One explanation for this result is that risk has a very negative meaning in the Islamic context. Thus, actions including risk are forbidden as they are sins according to the Koran. Furthermore, Benjamin, Choi, and Fisher [7] found Catholics to be less risk prone than Protestants and Jews. There are further studies which try to capture the effect of religion and religiousness on risk attitudes. Several studies have already shown that religiousness is linked to risk aversion [26]. In general, religious individuals seem to be more risk-averse than atheists. For instance, firms with a local base in a country with higher religiousness are less willing to take on risk (ibid.). Since being irreligious was a risky behaviour in Western (Christian and Muslim) societies, atheists were more risk prone. In contrast, being irreligious in Eastern (Hindu and Buddhist) societies did not reflect risk-taking behaviour. Therefore, being atheist in these countries is not correlated with risk tolerance [30]. As women are generally said to be more risk averse, the higher level of religiousness among women can also be explained by their risk preferences [31].

Although there are several studies analysing differences in attitudes towards risk with respect to the cultural background, there is still a lack of studies covering this topic with data from European countries. This motivates using the data presented in section 3.1. Furthermore, the literature review showed that there are still some doubts about the effects of several variables. This problem is also addressed by this study.

\section{Data and Estimation Procedure}

\subsection{Data}

In this paper, we use a panel data set provided by the German Institute for Economic Research (DIW). This German Socio-Economic Panel Study (SOEP) was first conducted in 1984. There are 27 waves of the SOEP up to now. This paper uses results from the 2009 questionnaire as this contains some specific questions about risk aversion. The advantage of this data set is that it contains more than 22,000 individuals. Further information about the data set can be found in the article by Wagner, Frick, and Schupp [41].

In total, there are eight different variables covering risk preferences in this data set. The first is the personal willingness to take risks. Participants are asked to selfassess their risk preferences on an 11-point scale with values between 0 (risk averse) and 10 (fully prepared to risks). The exact wording of the question is: "How do you see yourself: Are you generally a person who is fully prepared to take risks or do you try to avoid taking risks?". In addition, there are questions relating to risk taking behaviour in specific situations. Among these is risk tolerance while driving, in financial matters, in sports and leisure, and in occupation. Furthermore, there are questions dealing with willingness to take health risks and risk in trusting other people. The last one asks how much people would like to invest in a game after winning the lottery. We focus on the general willingness to take risks and the willingness to take risks on financial matters as these are the most important in an economic context. The exact wording for the question about risk tolerance in financial matters is: "People can behave differently in different situations. How would you rate your willingness to take risks in the following areas?". Here participants are asked about their risk tolerance in financial matters. Table 1 shows the relative frequencies of answers to the questions about risk tolerance.

Table 1. Relative Frequencies of Answers to Questions about Risk Tolerance (Source: GSOEP 2009).

\begin{tabular}{lll}
\hline Value & $\begin{array}{l}\text { General willingness to } \\
\text { take risks }\end{array}$ & $\begin{array}{l}\text { Willingness to take risks } \\
\text { in financial matters }\end{array}$ \\
\hline No Answer & 0.41 & 1.54 \\
0 & 9.21 & 37.69 \\
1 & 7.55 & 14.03 \\
2 & 14.48 & 15.27 \\
3 & 16.16 & 11.3 \\
4 & 11.39 & 5.75 \\
5 & 20.06 & 7.9 \\
6 & 9.03 & 2.53 \\
7 & 7.36 & 1.96 \\
8 & 3.41 & 1.24 \\
9 & 0.55 & 0.33 \\
10 & 0.38 & 0.46 \\
\hline
\end{tabular}

This table shows the proportion of people answering the questions about general risk preferences and risk tolerance in financial matters. Also the proportion of participants who did not answer that question is shown. According to survey about general risk tolerance, more than 30 per cent consider themselves as very risk averse (values of 0,1 , or 2 ). Around 27 per cent are moderately risk averse (values of 4 or 5) and 20 per cent take an average position (value of 5). 16 per cent of the participants assess themselves as moderately risk prone (values of 6 or 7), while only 4 per cent are highly risk tolerant (values of 8,9 , or 10 ). The amount of people being highly risk averse is highest in the context of risk taking in financial matters. Thus, more than 66 per cent consider themselves as very risk averse (values of 0,1 , or 2 ) in this context.

This analysis uses several different independent variables. Among these are gender, marital status, number of children, age, a dummy for a university degree, salary, and wealth as these are routinely included in all estimations of determinants of risk aversion. Furthermore, we use variables for political position, the degree of worries about financial markets, the current health status, a variable covering expectations about the future, the degree of life and income satisfaction, and a dummy for being unemployed and for those who are planning to leave the 
labour force in the following two years. As the main question of this study is whether the cultural background influences risk tolerance, we include variables for the nationality, the religion, and the religiousness of an individual participating in this survey. Although it would also be reasonable to cluster participants in regional groups, it is most intuitive to use someone's nationality as explanatory variable. As regions like Eastern Europe are not clearly defined, it would be very arbitrary to add people to groups with different nationalities. Thus, this study uses dummies for nationalities and not for the regional background.

All variables are taken from the 2009 sample with exception of the variables for religion and wealth which are taken from the 2007 sample because these variables were not included in the 2009 sample. As data sets had to be merged, the maximum number of observations decreased to roughly 17,000 .

\subsection{Estimation Procedure}

The dependent variable in this study is a variable with 11 different possible values. However, we cannot say anything about the differences between two outcomes. The only valid conclusion is to put people in order according to their self-assessment. This means that the dependent variable is an ordinal one. Therefore, it is not useful to use a simple linear regression framework (like, e.g., [5]) as this requires a metric measurement level. The problem is that OLS estimators are not efficient as they do not provide the minimum variance estimator in this context. Furthermore, the standard errors would be biased using an OLS regression. Other papers, therefore, use different techniques like interval regressions [19]. In this paper, we use an ordinal logit model. However, the problem is that a simple ordinal logit model uses the proportional odds assumption. This means that the model has the same coefficients for all values of the dependent variable. This assumption is often violated. A procedure for testing the proportional odds assumption is the Brant Test of parallel regression assumption [9]. Running this test reveals that the assumption is violated for all estimations presented here. A solution to overcome this problem is to use a generalized ordered logit model. In this case, we use the generalized ordered logit model provided by R. Williams [44]. After estimating this model, average marginal effects are computed. However, every model was also estimated using an ordinal logit model. The estimations show very similar results.

\section{Estimation Results}

In this section, the results of the estimation of the variables that influence risk taking behaviour are presented. As mentioned in the last section, we use a generalized ordered logit model. Since all estimations contain a huge amount of coefficients, we will not discuss every single value. Thus, the first step is to present and discuss the estimation results with respect to each dependent variable. Then the differences between the estimations are discussed.

First, we take a look at the determinants of the general attitudes towards risk. Results of the estimations are shown in Table 2 and 3. The coefficient of the dummy for women (Woman) has the expected effect on risk taking behaviour. Thus, women have a higher probability of being risk averse (values from 0 to 3 ). On the other hand, they have a lower probability of being risk prone (values from 6 to 9). The same accounts for being married (Married). In contrast to previous studies [22], risk tolerance is positively correlated with the number of children (Children). However, this study uses a variable for children not living at home while previous studies used the number of children living at home. One explanation might be that parents are only more risk averse if they have young children living at home that they have to care for. If they are old enough to live alone and if they earn their own money, parents can again focus on their own situation. Furthermore, parents might expect that adult children care for them if they have financial problems or if they are in need for care.

As in previous studies, risk propensity decreases with age (Age). Elderly individuals are more likely to be very risk averse and less likely to be more risk tolerant. Previous studies showed a correlation between education or cognitive ability and risk tolerance. Thus, a dummy variable for having a university degree (Uni) was included. In contrast to other studies [8] higher education did not have explanatory power in this model. Therefore, it is not included in Tables 2 and 3.

On the contrary, income (Salary) has the expected effect on attitudes towards risk. Thus, the higher the income, the lower the probability of being very risk averse. Salary significantly decreases the likelihood of being relatively risk neutral or moderately risk prone. In the first model, however, it decreases the likelihood of being relatively riskneutral (value of 5). Wealth has, to a large extent, the expected effect. It decreases the probability of being very risk averse and increases the probability of being more risk tolerant (values of 5 and 9). However, the connection between being rich and being moderately (value of 7) or very risk prone (value of 9) is ambiguous. However, these coefficients are significant only at the $10 \%$ level of significance and should therefore not be over-interpreted.

Besides those variables that are routinely included in estimations of risk taking behaviour there are several other variables that matter in this estimation. The first one is a variable which shows how worried respondents are about their finances (Worries about Finances). The response is measured on a 3-point scale. The higher the value of this variable is, the smaller the worries are about finances. Therefore, people with large worries about finances have a higher probability of being very risk averse and have a lower probability of being moderately risk averse. On the other hand, people with virtually no worries about finances 
are not significantly more likely to be risk prone. In the first model they even are less likely to be very risk prone (value of 9). One explanation might be that if one is not concerned about his future, he or she does not have to behave risky in order to achieve a better situation in the future as the person is already convinced about his or her future perspectives.

Table 2. Determinants General Willingness to Take Risks 1.

\begin{tabular}{|c|c|c|c|c|c|c|c|c|c|c|c|}
\hline \multirow[b]{2}{*}{ Variable } & \multicolumn{11}{|c|}{ General Willingness to Take Risks } \\
\hline & $\mathbf{0}$ & 1 & 2 & 3 & 4 & 5 & 6 & 7 & 8 & 9 & 10 \\
\hline Woman & $36.6287 * * *$ & $33.6265 * * *$ & $51.7889 * * *$ & $14.1364 * *$ & -3.0360 & $-28.5884 * * *$ & $-38.0846 * * *$ & $-42.6988 * * *$ & -19.2099 & -3.9143 & -0.6357 \\
\hline Married & -4.4862 & 9.8416 & $20.7106^{* *}$ & 14.8086 & -3.1293 & -2.7714 & $-13.8105^{* *}$ & $-9.6739 *$ & -8.0364 & -1.2605 & -1.2699 \\
\hline Children & -14.2300 & -6.5482 & $-14.9890^{*}$ & -11.1870 & $-20.1939 * *$ & $21.7013 * *$ & $22.6407 * * *$ & 9.9683 & 6.5423 & 2.8605 & 2.2598 \\
\hline Age & $2.2694 * * *$ & $1.3000^{* * *}$ & $1.6338 * * *$ & -0.3279 & $-0.6137 * * *$ & $-2.0227 * * *$ & $-1.1539 * * *$ & $-1.0119 * * *$ & -0.1079 & -0.0218 & 0.0228 \\
\hline Salary & -0.0000 & $-0.0068 * * *$ & 0.0034 & 0.0003 & $0.0048^{*}$ & $-0.0052 * *$ & $0.0064 * * *$ & $0.0033^{* * *} *$ & 0.0026 & 0.0002 & 0.0001 \\
\hline Wealth & -0.0001 & -0.0000 & -0.0000 & -0.0000 & $0.0001 * *$ & $0.0001 * *$ & -0.0000 & -0.0000 & 0.0000 & 0.0000 & -0.0000 \\
\hline $\begin{array}{c}\text { Worries } \\
\text { about } \\
\text { Finances }\end{array}$ & -23.3274 & -2.4813 & 2.2775 & $15.0574 * * *$ & -0.0065 & $10.0187 * *$ & 0.0803 & 2.7537 & -1.6345 & -1.7658 & 0.0228 \\
\hline Satisfaction & -3.5289 & $-4.6500 * * *$ & -1.8570 & $-3.7077 * *$ & -0.9560 & -1.6918 & $3.6056^{* * *}$ & $7.9951 * * *$ & 4.4944 & 0.6883 & -0.0708 \\
\hline $\begin{array}{l}\text { Current } \\
\text { Health }\end{array}$ & 1.1397 & $4.3266^{* * *}$ & $9.6468 * * *$ & $10.9088 * * *$ & $-6.6899 * *$ & -0.9067 & $-9.3678 * * *$ & $-3.6084 *$ & -3.9882 & 0.2037 & -1.2147 \\
\hline Unemployed & -5.6465 & -6.8454 & 10.6172 & $31.1442 * *$ & $20.5811^{*}$ & $-31.1210^{* *}$ & 5.0149 & 3.5613 & -22.5007 & -1.9313 & -3.0346 \\
\hline $\begin{array}{l}\text { Exit Labour } \\
\text { Force }\end{array}$ & -0.5444 & -0.1296 & -0.2578 & 0.2181 & -0.1127 & 0.0896 & $0.5227 * * *$ & 0.1366 & 0.0498 & 0.0213 & 0.0096 \\
\hline $\begin{array}{l}\text { Political } \\
\text { Attitudes }\end{array}$ & 0.4020 & $-4.7959 * * *$ & $-8.8499 * * *$ & $-6.1883 * * *$ & 0.3111 & $6.0454 * * *$ & $6.4985 * * *$ & $4.2536 * * *$ & 1.776 & 0.4625 & 0.2705 \\
\hline Turkish & 46.8124 & 19.6591 & 33.2373 & -42.5201 & -19.6670 & $-71.3463 * *$ & $52.7181 * *$ & -13.3866 & -6.3593 & -998.9183 & 996.9604 \\
\hline Italian & 12.8180 & 7.5954 & 24.0723 & $-62.0352 * *$ & -9.0327 & 29.3666 & -18.9234 & -9.8398 & 17.2643 & 6.6709 & 3.6914 \\
\hline Yugoslav & 49.0602 & -39.6255 & -31.6589 & 14.0820 & -17.9200 & 9.5991 & 6.4817 & $-51.9039 *$ & 31.7527 & 15.4225 & 16.2079 \\
\hline Greek & 54.0416 & $-50.3868 * *$ & 65.7576 & -5.2246 & 30.0135 & -4.8824 & $-68.8976 * * *$ & -3.9050 & -12.3178 & -6.5567 & 0 (omitted) \\
\hline Austrian & 0.2487 & 17.1885 & -25.3033 & 84.2712 & $-103.658 * * *$ & -12.6057 & 33.059 & 12.5105 & 2.1035 & -6.3298 & 0 (omitted) \\
\hline Protestant & -7.5149 & $-7.8281^{*}$ & -7.2088 & 2.0007 & 4.1206 & 6.4494 & 5.4677 & 2.7409 & 2.7421 & -0.2273 & -0.3023 \\
\hline Atheist & $-20.1409 * * *$ & $-16.5295 * * *$ & $-13.4319 *$ & -2.3733 & 6.4332 & $31.8079 * * *$ & -0.0833 & $12.5429 * * *$ & 2.3083 & 0.0675 & -0.4474 \\
\hline Muslim & -0.8784 & 3.1925 & -7.1698 & -7.5583 & 10.7915 & 15.4903 & $-30.8557 * *$ & 3.9797 & 8.7611 & 8.3408 & -2.9248 \\
\hline & & \multicolumn{3}{|c|}{ Number of Observations } & 17230 & LR chi & $2(154)$ & 2942.38 & \multicolumn{2}{|c|}{ Pseudo R2 } & 0.0398 \\
\hline
\end{tabular}

Note: The table shows estimation results of a generalized ordered logit model. The values show the average marginal effects of the respective coefficients. All values given in the table are multiplied by 1000 . The asterisks indicate whether a coefficient is significantly different from zero at the $10 \%$ (one asterisk), $5 \%$ (two asterisks) or $1 \%$ (three asterisks) significance level.

The degree of life satisfaction (Satisfaction) has a similar effect. Participants were asked how satisfied they are with their lives with respect to the last five years. The estimation shows that more satisfied people tend to be less risk averse. Moreover, those individuals with higher degrees of life satisfaction are more likely to be moderately or very risk prone. This is in contrast to Prospect Theory which says that people tend to be risk prone if they are below a subjective reference point (this could be the income level). On the other hand, people tend to be risk averse if they are above this reference point. The results reveal exactly the opposite. Being highly satisfied increases the probability of being risk prone and vice versa. Although we do not know where the reference points for the participants are, we can conclude that people who are highly satisfied are above what they refer to as their reference point.

Current health status (Current health) also has some impact on risk attitudes. Participants were asked about their current health status. The higher the value is, the worse the health status is. Thus, a bad health status raises the probability of being risk averse and decreases the probability of being moderately or very risk prone. Furthermore, a dummy for being unemployed (Unemployed) is included. The unemployed show a higher probability of being moderately risk averse and a lower probability of being risk neutral or very risk prone. The overall result of all those variables is that being in an uncomfortable situation (e.g. being unemployed or having a bad health status) leads people to be more risk averse as they might be concerned about potential losses. An alternative explanation might be that people tried risky behaviour in the past and lost and are therefore now both in an unsatisfying situation and also risk averse due to negative experiences.

Moreover, planning to leave occupation in the following two years (Exit Labour Force) decreases the probability of being completely risk averse. It also makes it more likely that somebody is moderately risk prone. Furthermore, the political position (Political Attitudes) can partly explain attitudes towards risk. People were asked how they self-assess themselves on a left-right scale according to their political attitudes. This variable is measured on an 11-point scale with a value of 1 meaning that an individual says about himself or herself that he or she is completely left-wing. According to their self-assessment, the overall majority of people is neither left wing nor right wing as they have a 4,5 or 6 on this scale. Roughly ten per cent are moderately right 
and roughly 18 per cent are moderately left. According to the results in Table 2 and Table 3, being more leftwing increases the probability of being very risk averse. In contrast, being less left-wing increases the likelihood of being relatively risk neutral, moderately risk prone and very risk prone. This may be explained by the fact that the left-wing tend to favour equality in contrast to liberty. Thus, they also dislike situations in which people can achieve unequal results. Consequently, they try to avoid risky choices and favour situations with certain outcomes.

Table 3. Determinants General Willingness to Take Risks 2.

\begin{tabular}{|c|c|c|c|c|c|c|c|c|c|c|c|}
\hline \multirow[b]{2}{*}{ Variable } & \multicolumn{11}{|c|}{ General Willingness to Take Risks } \\
\hline & $\mathbf{0}$ & 1 & 2 & 3 & 4 & 5 & 6 & 7 & 8 & 9 & 10 \\
\hline Woman & $36.6287 * * *$ & $33.6265 * * *$ & $51.7889 * * *$ & $14.1364 * *$ & -3.0360 & $-28.5884 * * *$ & $-38.0846^{* * *}$ & $-42.6988 * * *$ & 19.2099 & -3.9143 & -0.6357 \\
\hline Married & -4.4862 & 9.8416 & $20.7106^{* *}$ & 14.8086 & -3.1293 & -2.7714 & $-13.8105^{* *}$ & $-9.6739 *$ & -8.0364 & -1.2605 & -1.2699 \\
\hline Children & -14.2300 & -6.5482 & $-14.9890 *$ & -11.1870 & $-20.1939 * *$ & $21.7013 * *$ & $22.6407 * * *$ & 9.9683 & 6.5423 & 2.8605 & 2.2598 \\
\hline Age & $2.2694 * * *$ & $1.3000 * * *$ & $1.6338 * * *$ & -0.3279 & $-0.6137 * * *$ & $-2.0227 * * *$ & $-1.1539 * * *$ & $-1.0119 * * *$ & -0.1079 & -0.0218 & 0.0228 \\
\hline Salary & -0.0000 & $-0.0068 * * *$ & 0.0034 & 0.0003 & $0.0048^{*}$ & $-0.0052^{* *}$ & $0.0064 * * *$ & $0.0033 * * *$ & 0.0026 & 0.0002 & 0.0001 \\
\hline Wealth & -0.0001 & -0.0000 & -0.0000 & -0.0000 & $0.0001 * *$ & $0.0001 * *$ & -0.0000 & -0.0000 & 0.0000 & 0.0000 & -0.0000 \\
\hline $\begin{array}{c}\text { Worries } \\
\text { about } \\
\text { Finances }\end{array}$ & -23.3274 & -2.4813 & 2.2775 & $15.0574 * * *$ & -0.0065 & $10.0187 * *$ & 0.0803 & 2.7537 & -1.6345 & -1.7658 & 0.0228 \\
\hline Satisfaction & -3.5289 & $-4.6500 * * *$ & -1.8570 & $-3.7077 * *$ & -0.9560 & -1.6918 & $3.6056^{* * *}$ & $7.9951 * * *$ & 4.4944 & 0.6883 & -0.0708 \\
\hline $\begin{array}{l}\text { Current } \\
\text { Health }\end{array}$ & 1.1397 & $4.3266^{* *}$ & $9.6468 * * *$ & $10.9088 * * *$ & $-6.6899 * *$ & -0.9067 & $-9.3678 * * *$ & $-3.6084 *$ & -3.9882 & 0.2037 & -1.2147 \\
\hline Unemployed & -5.6465 & -6.8454 & 10.6172 & $31.1442 * *$ & $20.5811 *$ & $-31.1210 * *$ & 5.0149 & 3.5613 & $\begin{array}{c}- \\
22.5007\end{array}$ & -1.9313 & -3.0346 \\
\hline $\begin{array}{c}\text { Exit Labour } \\
\text { Force }\end{array}$ & -0.5444 & -0.1296 & -0.2578 & 0.2181 & -0.1127 & 0.0896 & $0.5227 * * *$ & 0.1366 & 0.0498 & 0.0213 & 0.0096 \\
\hline $\begin{array}{l}\text { Political } \\
\text { Attitudes }\end{array}$ & 0.4020 & $-4.7959 * * *$ & $-8.8499 * * *$ & $-6.1883 * * *$ & 0.3111 & $6.0454 * * *$ & $6.4985 * * *$ & $4.2536 * * *$ & 1.776 & 0.4625 & 0.2705 \\
\hline Turkish & 46.8124 & 19.6591 & 33.2373 & -42.5201 & -19.6670 & $-71.3463 * *$ & $52.7181 * *$ & -13.3866 & -6.3593 & $\begin{array}{c}- \\
998.9183\end{array}$ & 996.9604 \\
\hline Italian & 12.8180 & 7.5954 & 24.0723 & $-62.0352 * *$ & -9.0327 & 29.3666 & -18.9234 & -9.8398 & 17.2643 & 6.6709 & 3.6914 \\
\hline Yugoslav & 49.0602 & -39.6255 & -31.6589 & 14.0820 & -17.9200 & 9.5991 & 6.4817 & $-51.9039 *$ & 31.7527 & 15.4225 & 16.2079 \\
\hline Greek & 54.0416 & $-50.3868 * *$ & 65.7576 & -5.2246 & 30.0135 & -4.8824 & $-68.8976 * * *$ & -3.9050 & $\begin{array}{c}- \\
12.3178\end{array}$ & -6.5567 & $\begin{array}{c}0 \\
\text { (omitted) }\end{array}$ \\
\hline Austrian & 0.2487 & 17.1885 & -25.3033 & 84.2712 & $-103.658 * * *$ & -12.6057 & 33.059 & 12.5105 & 2.1035 & -6.3298 & $\begin{array}{c}0 \\
\text { (omitted) }\end{array}$ \\
\hline Protestant & -7.5149 & $-7.8281 *$ & -7.2088 & 2.0007 & 4.1206 & 6.4494 & 5.4677 & 2.7409 & 2.7421 & -0.2273 & -0.3023 \\
\hline Atheist & $-20.1409 * * *$ & $-16.5295 * * *$ & $-13.4319 *$ & -2.3733 & 6.4332 & 31.8079 *** & -0.0833 & $12.5429 * * *$ & 2.3083 & 0.0675 & -0.4474 \\
\hline Muslim & -0.8784 & 3.1925 & -7.1698 & -7.5583 & 10.7915 & 15.4903 & $-30.8557 * *$ & 3.9797 & 8.7611 & 8.3408 & -2.9248 \\
\hline & & \multicolumn{3}{|c|}{ Number of Observations } & 17230 & \multicolumn{2}{|c|}{ LR chi2(154) } & 2942.38 & \multicolumn{2}{|c|}{ Pseudo R2 } & 0.0398 \\
\hline
\end{tabular}

Note: The table shows estimation results of a generalized ordered logit model. The values show the average marginal effects of the respective coefficients. All values given in the table are multiplied by 1000 . The asterisks indicate whether a coefficient is significantly different from zero at the $10 \%$ (one asterisk), $5 \%$ (two asterisks) or $1 \%$ (three asterisks) significance level.

Lastly, we discuss the role of cultural background as this is the main purpose of this paper. The effect of being a foreigner is ambiguous. It increases the probability of being maximally risk averse and also of being very risk prone. This could be explained by the fact that the group of foreigners in this data set is heterogeneous. It consists of people living in Germany for many years and people who immigrated just a few years ago. Some argue that immigration is a risky behaviour. Thus, immigrants should have a higher risk propensity. On the other hand, individuals might be risk averse after they moved to another country. Therefore, we need to take a closer look at certain nationalities. The data set provides information about Germans, Turks (Turkish), Italians (Italian), immigrants from the former Yugoslavia (Yugoslav), Greeks (Greek), and Austrians (Austrian). The other groups of nationalities of participants in the GSOEP are simply too small to use them in this analysis. Table 3 shows that all variables covering nationality have some explanatory power. Thus, Greeks have a lower probability of being very risk averse and Austrians and Italians have a lower probability of being moderately risk averse. Furthermore, Greeks and Yugoslavs are less likely to be moderately risk prone. Turks, on the other hand, have a lower probability of being relatively risk neutral but a higher probability of being moderately risk prone. The results show that national background does indeed have some impact on risk tolerance. This is contrast to the result of Bartke and Schwarze [5]. Furthermore, this study enhances other studies showing that not only the race matters but also the nationality. Moreover, the results are in contrast to the study of Cummings, Harnett, and Stevens [17] which found Greeks to be less risk averse than Germans. This, however, might be explained by differences between Greek 
participants who emigrated from Greece and Greeks who still live in their home country.

The cultural background is not only defined by someone's nationality but also by his or her religion. Thus, dummies for different religions and denominations are included in this analysis. In the first estimation, dummy variables for being Protestant and being atheist are included. The reference group consists of Catholics, Muslims and Christians with other denominations (Table 2). According to the estimations presented in Table 2, religion is indeed of importance. The results are in line with Benjamin, Choi, and Fisher [7] showing that Protestants (Protestant) have a lower probability of being very risk averse. Similarly, being atheist (Atheist) decreases the likelihood of being very risk averse. However, atheists are also more likely to be risk neutral and moderately risk prone. Both effects can partly be explained by German history. Being atheist was a risky behaviour in the past as these people were prosecuted. Also Protestants had to fight for their faith and were prosecuted in several regions in which Catholicism was the dominant denomination. In the second estimation (Table 3), we also tested whether being Muslim plays a role. It decreased the probability of being moderately risk prone. In contrast to other studies, this variable seems to have minor importance. This means that the higher risk aversion among Turks cannot solely be explained by their religion. In contrast to the study of Hilary and Hui [26] religiousness is not important in this estimation. Religiosity is measured by the frequency of attending religious services. Higher values mean that people go less often to church. Hence, there is no evidence that more religious people are more risk averse.

The data set does not only provide information about general risk attitudes but also about risk aversion in financial matters (see Table 4). The estimations show very similar results. Contrary to the previous example, educational background is a relevant factor in this context. Having a university degree lowers the likelihood of being completely risk averse. Accordingly, the effect of education seems to depend on the context. Thus, the educational background is more important in the context of financial decision than in the context of general decisions. Life and income satisfaction (Income Satisfaction) largely have the same effect. More satisfied people tend to be less risk averse. In contrast to the previous estimation, current health status does not play a role in explaining the attitudes towards financial risk.

Table 4. Determinants Willingness to Take Risks in Financial Matters.

\begin{tabular}{|c|c|c|c|c|c|c|c|c|c|c|c|}
\hline \multirow[b]{2}{*}{ Variable } & \multicolumn{11}{|c|}{ General Willingness to Take Risks } \\
\hline & $\mathbf{0}$ & 1 & 2 & 3 & 4 & 5 & 6 & 7 & 8 & 9 & 10 \\
\hline Woman & $111.5097 * * *$ & $23.8152 * * *$ & -0.8330 & $-29.8376 * * *$ & $-24.1800 * * *$ & -33.9031 & -18.5817 & -19.1916 & -5.7968 & -0.5032 & -3.2654 \\
\hline Married & -20.7281 & $30.1510 * * *$ & 2.0183 & -3.4629 & -2.3147 & 3.3059 & -2.1737 & -4.5396 & 2.547 & -0.0612 & -1.6303 \\
\hline Children & $-47.9488 * * *$ & -0.842 & 3.2758 & $15.6452 *$ & 2.8639 & 21.2823 & 6.0454 & -1.3377 & -0.7164 & 1.3409 & -0.0965 \\
\hline Age & $4.9420 * * *$ & -0.2238 & $-1.6235 * * *$ & $-1.1295 * * *$ & $-0.5431 * * *$ & -1.0767 & -0.3032 & -0.2178 & 0.0175 & -0.0291 & 0.1176 \\
\hline Uni & $-57.7216^{* *}$ & 5.1841 & 10.6571 & 2.942 & 0.0188 & 25.3064 & 7.1121 & 3.2447 & 5.6183 & -2.7239 & -0.0209 \\
\hline Salary & -0.0271 & -0.0026 & $0.0112 * * *$ & $0.0070^{* * *}$ & $0.0030 * * *$ & 0.0060 & 0.0026 & 0.0011 & 0.0020 & -0.0000 & 0.0002 \\
\hline Wealth & $-0.0008 * * *$ & -0.0000 & $0.00038 * * *$ & $0.0002 * * *$ & $0.0002 * * *$ & 0.0001 & 0.0000 & 0.0000 & 0.0000 & 0.0000 & -0.0000 \\
\hline $\begin{array}{l}\text { Worries } \\
\text { about } \\
\text { Finances }\end{array}$ & -41.8039 & 2.1031 & $17.0057 * * *$ & $12.5989 * * *$ & 3.3596 & $7.9094 * *$ & -0.1930 & 4.3347 & -2.1476 & -0.8285 & -0.7836 \\
\hline Satisfaction & -1.7245 & -1.2014 & $-3.2173 *$ & 1.5013 & 0.9916 & 1.4585 & 1.1296 & 1.1353 & 0.4310 & -0.3036 & 0.2575 \\
\hline $\begin{array}{c}\text { Income } \\
\text { Satisfaction }\end{array}$ & -2.9627 & -1.6674 & 0.2940 & 0.8389 & 1.2499 & 0.8567 & 0.6359 & 0.5174 & 0.5805 & 0.1946 & -0.3206 \\
\hline Unemployed & $59.5558 * * *$ & $-27.1381 * *$ & -14.0045 & $-20.6924^{*}$ & -3.2836 & -4.9445 & -5.1374 & 2.1096 & 7.3270 & 1.8993 & 4.0863 \\
\hline $\begin{array}{l}\text { Exit Labour } \\
\text { Force }\end{array}$ & -1.5129 & -0.0623 & 0.1699 & $0.4841 * * *$ & $0.2591 * * *$ & 0.03452 & 0.1669 & 0.0708 & 0.0970 & 0.0330 & 0.0108 \\
\hline Future & $-25.2404 * * *$ & -4.0622 & -0.9797 & $7.8503 * *$ & $7.1771 * * *$ & 6.0501 & 3.8825 & 0.3435 & 3.5843 & 1.027 & 0.6755 \\
\hline $\begin{array}{l}\text { Political } \\
\text { Attitudes }\end{array}$ & -6.2672 & $-6.0187 * * *$ & -0.9642 & $2.4691 *$ & 1.5106 & 5.7285 & 1.9644 & 1.6405 & 0.1809 & 0.2949 & 0.1272 \\
\hline Turkish & $105.8463^{* *}$ & -44.2596 & $-65.5218 * * *$ & -44.3263 & 14.1316 & 4.4613 & 8.2095 & -2.3868 & 20.628 & 4.1591 & 0.1941 \\
\hline Italian & $127.077 * *$ & $-51.3643 * *$ & -28.0912 & -36.3877 & -33.6393 & -14.9026 & 16.6177 & -6.7851 & 9.1431 & 12.5342 & 3.1859 \\
\hline Yugoslav & 138.5930 & -75.2398 & -54.8582 & $-87.9557 * *$ & 23.4537 & 58.2505 & -8.6622 & 28.9549 & $-1012.9 * *$ & $997.033 * * *$ & $*-2.2742 * * *$ \\
\hline Greek & 83.3916 & 84.003 & -41.7118 & $-83.3443 * * *$ & -8.0792 & -13.8748 & 10.9255 & $-1017.4 * * *$ & $989.87 * * *$ & -5.7869 & 0 (omitted) \\
\hline Austrian & 73.3649 & -33.2721 & -11.7658 & 1.4212 & 20.3459 & 6.9696 & $-1022.8 * * *$ & 595.4719 & 380.2476 & -5.6582 & 0 (omitted) \\
\hline Protestant & -5.0535 & $-13.6563 *$ & $15.2233 * *$ & 6.6747 & 3.0637 & -5.5498 & 0.8331 & 1.9709 & -1.571 & 0.1817 & -1.7545 \\
\hline Atheist & -15.477 & -7.3105 & $14.5607^{*}$ & 0.4157 & 0.5568 & 4.6851 & 0.6533 & 4.7131 & -0.9218 & -0.0203 & 0.281 \\
\hline Muslim & 11.3717 & -20.0713 & -37.1326 & 15.0113 & 4.2098 & 8.8984 & -7.4781 & 7.9743 & 0.9953 & 5.1834 & 2.1687 \\
\hline \multirow[t]{2}{*}{ Service } & $-20.2613 * *$ & $6.5136^{*}$ & $9.8484 * * *$ & 1.9988 & 2.4820 & -0.4232 & 0.2161 & 2.627 & -1.7854 & -0.3158 & -0.4216 \\
\hline & & & $\begin{array}{c}\text { Number of } \\
\text { Observations }\end{array}$ & \multicolumn{2}{|c|}{17230} & $\operatorname{chi} 2(154)$ & \multicolumn{2}{|c|}{2619.40} & Pseudo R2 & \multicolumn{2}{|c|}{0.0408} \\
\hline
\end{tabular}

Note: The table shows estimation results of a generalized ordered logit model. The values show the average marginal effects of the respective coefficients. All values given in the table are multiplied by 1000 . The asterisks indicate whether a coefficient is significantly different from zero at the $10 \%$ (one asterisk), $5 \%$ (two asterisks) or $1 \%$ (three asterisks) significance level.

Again, foreigners have a higher probability of being completely risk averse. However, they are also less likely to 
be very risk averse (value of 2) and more likely to be risk neutral. Thus, being very risk prone is positively correlated with non-German nationality. The next step is to look more closely at specific nationalities. The effects are ambiguous for Yugoslavs, Greeks, and Italians. However, being Turkish or Italian is positively correlated with being very risk averse. The next question is then whether religion matters in this context. The effect of being Protestant is ambiguous. It decreases the likelihood of having a value of 1 but increases the likelihood of having a value of 2 . Atheists, on the other hand, tend to be more risk prone. The coefficients for the dummy for Islamic faith are again not significantly different from zero. In contrast to the previous estimation, religiousness (Service) is of importance in this estimation. Thus, religiousness is positively correlated with being completely risk averse but negatively correlated with being very risk averse (values of 1 or 2). Hence, this estimation supports the view that religious people are more risk averse [26]. It is noteworthy that there are hardly any significant variables in the generalized ordered logit model for values above 5 . This can mainly be explained by the fact that there are simply very few people in the sample who are highly risk tolerant in financial matters (see Table $1)$.

The overall significance of the estimation is fairly good. The second model including dummies for nationality performs better than the first model. The model estimating the effects on willingness to take risks in financial matters performs even better than the first two models. We also run estimations for the other variables covering risk tolerance in this data set. The estimations show mainly very similar results confirming the major findings of this study. In addition, Dohmen et al. [49] tested the relationship between answers to the items in the GSOEP and real life decisions with non-participants of the survey. The correlation between the self-assessment and real life risk aversion is fairly high. This means that the self-assessment is a valid instrument to measure someone's risk tolerance. Thus, the results presented in this study can be generalized to other people not taking part in this survey.

\section{Conclusions}

Risk aversion is an important factor not only in economic situations but also in most life decisions. Thus, the aim of this study was to figure out which determinants can explain different attitudes towards risk. This study showed that women tend to be risk averters. Married individuals are also more likely to be risk averse. Age has the effect that it decreases risk tolerance. Both income and wealth are positively correlated with risk tolerance. Furthermore, the study found several other factors to be important that are not included in other estimations. For instance, people who plan to leave occupation in the following two years are more risk prone. Current health status plays a role in explaining general risk tolerance.
Political attitudes are also of relevance. Being less leftwing is associated with a higher probability of being risk prone.

The main issue of this study was to figure out possible differences in risk tolerance with respect to cultural background. The estimations revealed that both religion and nationality matter for risk aversion. Thus, both Protestants and atheists tend to be less risk averse than people with other religions or denominations. Furthermore, foreigners are less likely to be risk prone. This also applies for specific nationalities. Turks, Italians, Greeks, and ExYugoslavs tend to be more risk averse than others. This partly contradicts the hypothesis that migrants are more risk prone. However, this hypothesis might still hold. The main wave of migration into Germany was in the sixties. Thus, Turks, Italians, and Greeks immigrated several decades ago as guest workers. The participants in this survey are not all of the first generation of migrants. This partly explains why those groups no longer have a higher risk tolerance. Furthermore, Austrians did not have a significantly different risk tolerance to others with the exception of two cases. This can be explained by the fact that, to a large extent, Germans and Austrians share the same culture.

As cultural background does indeed have some impact on risk taking behaviour, one should take these results into consideration if one thinks, for instance, about reforms of the national social pension programme. In general, it could be useful to influence risk attitudes of individuals. The ratio of shareholder, for instance, is relatively low in Germany. However, it is difficult to change people's attitudes towards risk. Studies showed that the effect of financial literacy on risk tolerance is mixed. Thus, it might be useless to improve financial education in order to address specific groups. Furthermore, this study showed that risk tolerance is also influenced by the cultural background. It is therefore even more complicated to address these groups as the cultural background cannot be changed.

The main advantage of this study was that it used a survey with a large amount of participants. Furthermore, it applied a different estimation procedure in order to get more efficient results. The limitations of this study are that the results cannot be generalized to people with a specific nationality not living in Germany. For instance, Greeks and Turks living in their home country live in a different cultural environment. Thus, they might also have different attitudes towards risk with respect to Greeks and Turks living in Germany. Furthermore, the data set only includes information for some national groups. Therefore, it would be interesting to have further estimations with data sets from other countries.

All in all, one has to consider the cultural background if one wants to explain determinants of attitudes towards risks. As risk aversion is of major relevance in everyday life, it is necessary to keep this finding in mind when politicians or academics want to address these groups. 


\section{Acknowledgements}

The data used in this publication were made available by the German Socio-Economic Panel Study (GSOEP) at the German Institute of Economic Research (DIW Berlin), Berlin.

The author wishes to thank Juergen Kaehler and Doris Weck for very useful comments and suggestions.

\section{References}

[1] Agnew, J., P. Balduzzi, and A. Sundén. 2003. "Portfolio Choice and Trading in a Large 401(k) Plan" The American Economic Review 93(1): 193-215.

[2] Arano, K., C. Parker, and R. L. Terry. 2010. "Gender-Based Risk Aversion and Retirement Asset Allocation" Economic Inquiry 48(1): 147-155.

[3] Arrow, K. J. 1971. Essays in the Theory of Risk-Bearing. Amsterdam: North-Holland Pub. Co.

[4] Bajtelsmit, V. L., A. Bernasek, and N. A. Jianakoplos. 1999. "Gender Differences in Defined Contribution Pension Decisions" Financial Services Review 8(1): 1-10.

[5] Bartke, S. and R. Schwarze, 2008. "Risk-Averse by Nation or by Religion? Some Insights on the Determinants of Individual Risk Attitudes" SOEPpapers No. 131.

[6] Benjamin, D. J., J. J. Choi, and A. Strickland. 2010. "Social Identity and Preferences" The American Economic Review 100(4): 1913-1928.

[7] Benjamin, D. J., J. J. Choi, and G. Fisher. 2010. "Religious Identity and Economic Behavior" NBER Working Paper No. 15925.

[8] Bertaut, C. C. 1998. "Stockholding Behavior of U.S. Households: Evidence from the 1983-1989 Survey of Consumer Finances" The Review of Economics and Statistics 80(2): 263-275.

[9] Brant, R. 1990. "Assessing Proportionality in the Proportional Odds Model for Ordinal Logistic Regression" Biometrics 46(4): 1171-1178.

[10] Brown, D. A. 2007. "Pensions and Risk Aversion: The Influence or Race, Ethnicity, and Class on Investor Behavior" Lewis and Clark Law Review 11(2): 385-406.

[11] Brunnermeier, M. K. and S. Nagel. 2008. "Do Wealth Fluctuations Generate Time-Varying Risk Aversion? MicroEvidence on Individuals' Asset Allocation" The American Economic Review 98(3): 713-736.

[12] Cohen, A. and L. Einav. 2007. "Estimating Risk Preferences from Deductible Choice" The American Economic Review 97(3): 745-788.

[13] Cohn, R. A., W. G. Lewellen, R. Lease, and G. G. Schlarbaum. 2012. "Individual Investor Risk Aversion and Investment Portfolio Composition" The Journal of Finance 30(2): 605-620.

[14] Cole, S. A., A. Paulson, and G. K. Shastry. 2012. "Smart Money: The Effect of Education, Cognitive Ability, and
Financial Literacy on Financial Market Participation" Harvard Business School Finance Working Paper No. 09071.

[15] Coleman, S. 2003. "Risk Tolerance and the Investment Behavior of Black and Hispanic Heads of Household" Financial Counseling and Planning 14(2): 43-52.

[16] Croson, R. and U. Gneezy. 2009. "Gender Differences in Preferences" Journal of Economic Literature 47(2): 448474.

[17] Cummings, L. L., D. L. Harnett, and O. J. Stevens. 1971. "Risk, Fate, Conciliation and Trust: An International Study of Attitudinal Differences among Executives" The Academy of Management Journal 14(3): 285-304.

[18] Dohmen, T., A. Falk, D. Huffman, and U. Sunde, U. 2010. "Are Risk Aversion and Impatience Related to Cognitive Ability?" The American Economic Review 100(3): 12381260.

[19] Dohmen, T., A. Falk, D. Huffman, U. Sunde, J. Schupp, and G. G. Wagner. 2011. "Individual Risk Attitudes: Measurement, Determinants, and Behavioral Consequences" Journal of the European Economic Association 9(3): 522550 .

[20] Fan, J. X. and J. J. Xiao. 2006. "Cross-Cultural Differences in Risk Tolerance: A Comparison between Chinese and Americans" Journal of Personal Finance 5(3): 54-75.

[21] Friend, I. and M. E. Blume. 1975. "The Demand for Risky Assets" The American Economic Review 65(5): 900-922.

[22] Grazier, S. and P. J. Sloane. 2008. "Accident Risk, Gender, Family Status and Occupational Choice in the UK" Labour Economics 15(5): 938-957.

[23] Guiso, L. and M. Paiella. 2004. "The Role of Risk Aversion in Predicting Individual Behavior" CEPR Discussion Paper 4591.

[24] Gutter, M. S., J. J. Fox, and C. P. Montalto. 1999. "Racial Differences in Investor Decision Making" Financial Services Review 8(3): 149-162.

[25] Halek, M. and J. G. Eisenhauer. 2001. "Demography of Risk Aversion" The Journal of Risk and Insurance 68(1): 1-24.

[26] Hilary, G. and K. W. Hui. 2009. "Does Religion Matter in Corporate Decision Making in America?" Journal of Financial Economics 93(3): 455-473.

[27] Hsee, C. K. and E. U. Weber. 1999. "Cross-National Differences in Risk Preference and Lay Predictions" Journal of Behavioral Decision Making 12(2): 165-179.

[28] Jaeger, D. A., H. Bonin, T. Dohmen, A. Falk, D. Huffman, and U. Sunde, U. 2010. "Direct Evidence on Risk Attitudes and Migration" The Review of Economics and Statistics 92(3): 684-689.

[29] Levy, H. 1994. "Absolute and Relative Risk Aversion: An Experimental Study" Journal of Risk and Uncertainty 8(3): 289-307.

[30] Miller, A. S. 2000. "Going to Hell in Asia: The Relationship between Risk and Religion in a Cross Cultural Setting" Review of Religious Research 42(1): 5-18. 
[31] Miller, A. S. and J. P. Hoffmann. 1995. "Risk and Religion: An Explanation of Gender Differences in Religiosity" Journal for the Scientific Study of Religion 34(1): 63-75.

[32] Morin, R. A. and A. Fernandez Suarez. 1983. "Risk Aversion Revisited" The Journal of Finance 38(4): 12011216.

[33] Palsson, A.-M. 1996. "Does the Degree of Relative Risk Aversion Vary with Household Characteristics?" Journal of Economic Psychology 17(6): 771-787.

[34] Riley, W. B. and K. V. Chow. 1992. "Asset Allocation and Individual Risk Aversion” Financial Analysts Journal 48(6): 32-37.

[35] Salacuse, J. W. 1998. "Ten Ways that Culture Affects Negotiating Style: Some Survey Results" Negotiation Journal 14(3): 221-240.

[36] Shaw, K. L. 1996. "An Empirical Analysis of Risk Aversion and Income Growth" Journal of Labor Economics 14(4): 626-653.

[37] Siegel, F. W. and J. P. Hoban Jr. 1982. "Relative Risk Aversion Revisited" The Review of Economics and Statistics 64(3): 481-487.

[38] Sundén, A. E. and J. Surette. 1998. "Gender Differences in the Allocation of Assets in Retirement Savings Plans" The American Economic Review 88(2): 207-211.

[39] Sung, J. and S. Hanna. 1996. "Factors Related To Risk Tolerance" Financial Counseling and Planning 7(1): 11-19.

[40] Tanaka, T., C. F. Camerer, and Q. Nguyen. 2010. "Risk and Time Preferences: Linking Experimental and Household Survey Data from Vietnam" The American Economic Review 100(1): 557-571.

[41] Wagner, G. G., J. R. Frick, and J. Schupp. 2007. "The German Socio-Economic Panel Study (SOEP) - Scope, Evolution and Enhancements" Schmollers Jahrbuch 127(1): 139-169.

[42] Wang, M. and P. S. Fischbeck. 2008. "Evaluating Lotteries, Risks, and Risk-mitigation Programs" Journal of Risk Research 11(6): 775-795.

[43] Weber, E. U. and C. Hsee. 1998. "Cross-Cultural Differences in Risk Perception, but Cross-Cultural Similarities in Attitudes towards Perceived Risk" Management Science 44(9): 1205-1217.

[44] Williams, R. 2006. "Generalized Ordered Logit/Partial Proportional Odds Models for Ordinal Dependent Variables" The Stata Journal 6(1): 58-82. 